\title{
Prevalence of Obesity and its Influencing Factors in Affluent School Children of Tumkur: Lessons from South India
}

\author{
Sunil Kumar*, M. Amruth, Prashant Kumar, A.G. Balakrishna and M.C. Prabhudeva
}

Department of Community Medicine, Shridevi Institute of Medical Sciences and Research Hospital, Tumkur577501, Karnataka State, India

\begin{abstract}
Background: Obesity is defined by WHO "as a condition of abnormal or excessive fat accumulation in adipose tissue, to the extent that health may be impaired". The problem of childhood obesity is quite high in rich and affluent countries

1. To estimate the prevalence of obesity among school children aged 6-15 years in three affluent schools of Tumkur.

2. To study the influencing factors of obesity among school children.

Methods: Study Design: Case Control study.

Study Settings: Three affluent schools of Tumkur city, Karnataka, South India. Sample size was 2000 Students of three affluent schools and duration of study was from June to August 2014.

Each Child's height and weight were measured by adopting standard procedure. Body mass index (BMI) was calculated using BMI charts based on NCHS (national center for health statistics) standards. A child was considered obese if the BMI was $>95^{\text {th }}$ percentile cutoff point which is specific to the age and sex of the child. To determine the association of (life style) influencing factors of obesity in children, mothers were interviewed in presence of children to gather information' about their child's daily (24 hour) activity.

Results: Out of 2000 children 66 were obese. The prevalence was 3.3\% in school children in the age group of 6-15 years in three affluent schools of Tumkur. In our study, Prevalence of obesity was more in boys $(3.47 \%)$ on comparison to girls (3.04\%). There is increased prevalence of obesity in age group of six, eleven and twelve years. In this study $77.2 \%$ cases spent less than $2 \mathrm{hrs}$ in a day and $22.7 \%$ cases spent more than $2 \mathrm{hrs}$ in physical activities. Prevalence of obesity
\end{abstract} was more in children who spent less than $2 \mathrm{hrs}$ in a day in physical activities. This was statistically significant.

Conclusions: Prevalence of obesity in school children aged 6-15 yrs is 3.3\% in three affluent schools of Tumkur. Prevalence of obesity was more in boys on comparison with girls. Physical activity was the significant influencing factor of obesity among school children.

Keywords: School children, Obesity, BMI, Prevalance.

\section{BACKGROUND}

Obesity in children and adolescent is gradually becoming a major public health problem in developing countries, including India [1]. Obesity is defined by WHO "as a condition of abnormal or excessive fat accumulation in adipose tissue, to the extent that health may be impaired". The problem of childhood obesity is quite high in rich and affluent countries. Presently prevalence of child hood obesity is $>30 \%$ in America, $>20 \%$ in Australia [2] $>15 \%$ in U.K and Saudi Arabia [3]. In Greece, Italy, Malta, Portugal, China and Spain the prevalence is between 10-15\%. Recent investigation has shown that this problem started percolating even to the underdeveloped and developing countries, including India. As compiled by WHO prevalence of childhood obesity is over $2 \%$ in many developing countries. India is undergoing rapid transition in terms of economy, lifestyle, food habits etc.

*Address correspondence to this author at the Department of Community Medicine, Shridevi Institute of Medical Sciences and Research Hospital, Tumkur-577501, Karnataka State, India; Tel: +91-9880729089;

E-mail: drsunilkumar2006@gmail.com which is the factor responsible for increased prevalence of obesity in developing and underdeveloped countries.

Both over consumption of calories and reduced physical activities are involved in childhood obesity. Obesity is often expressed in terms of Body Mass Index.

Physical activity is defined as any bodily movement that results in energy expenditure [2].

Obesity predisposing to hypertension, cardiovascular, cancer etc is well recognized. Consequences of today's childhood obesity will be apparent in future. These problems will worse if obesity begins in early childhood. WHO has also emphasized the urgent need of understanding the prevalence trend and influencing factors of childhood obesity [3].

Because of the academic over load and home works children can't spend much of their time in games and sports. Games or physical training sessions are restricted or nonexistent in many schools. Children are 
forced to use their play time for the additional studies. Studies of young children suggest that lack of physical activity is a primary factor in excess fat accumulation. Most of the kids start out as active toddlers but by the time the enter high school about half of the girls and one fourth of the boys do not routinely practiced in physical activities [5].

The total amount of energy expanded depends on the characteristics of physical activity (Mode, Intensity, Duration and Frequency) and of the individual performing the exercise [5].

\section{AIMS AND OBJECTIVES}

1. To estimate the prevalence of obesity in school children aged 6-15 years in three affluent schools of Tumkur.

2. To study the influencing factors of obesity among school children.

\section{MATERIAL \& METHODS}

\section{Study Design}

The proposes case study was Case Control study.

\section{Study Settings}

Three affluent schools of Tumkur city, Karnataka, South India.

Those schools whose annual fees more than rupees 20,000 in Tumkur city were selected. Accordingly there were three affluent schools namely Don Bosco school, Lingapura, Jain Public school, Oorkere and Maruthi International school, Siddaganga Extension, Tumkur constituted the study area.

Before a school was taken for the study, head of the institution was contacted, purpose of the study was explained and consent was obtained. Sampled schools were visited on a prefixed date. Importance of the study was explained to the children and encouraged them to participate in the study. All the middle school children of the selected school of I-X standard of 6-15 years fulfilling inclusion criteria were studied.

A profile of Age, Sex, Class, section, Roll. No. of all students were recorded.

All the students studying in the three schools between $1^{\text {st }}$ Std to $10^{\text {th }}$ standard constituted study population. Each Child's height and weight were measured by adopting standard procedure. Body mass index (BMI) was calculated using BMI charts based on NCHS (national center for health statistics) standards [6].

Each Child height was measured in meters and weight was recorded in kilograms. formula

Body mass index (BMI) was calculated by using the

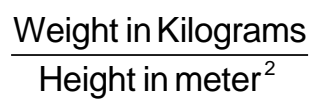

A child was considered obese if the BMI was $>95^{\text {th }}$ percentile cutoff point which is specific to the age and sex of the child (Table 1).

\section{Sample Size}

2000 Students of three affluent schools.

\section{Inclusion Criteria}

1) All the School children of $1^{\text {st }}-10^{\text {th }}$ standard of 3 affluent schools of Tumkur City.

2) Children aged between 6-15 years.

\section{Exclusion Criteria}

1) Children having chronic illness, endocrinal problems, severe malnutrition, physical mental defects and dwarfism.

2) Children aged below 6 years and above 15 years.

\section{Duration of Study}

June to August 2014.

\section{Cases}

Children were considered as obese based on NCHS (National Center for Health Statistics) standards.

BMI cut off points based on NCHS standards (2006)

\begin{tabular}{|c|c|c|}
\hline \multirow{2}{*}{ AGE IN YEARS } & \multicolumn{2}{|c|}{ BMI CUT OFF POINT } \\
\cline { 2 - 3 } & Boys & Girls \\
\hline \hline 6 & 18.5 & 18.9 \\
\hline 7 & 19.3 & 19.7 \\
\hline 8 & 20 & 20.6 \\
\hline 9 & 21 & 21.8 \\
\hline
\end{tabular}




\begin{tabular}{|c|c|c|}
\hline 10 & 22 & 23 \\
\hline 11 & 23 & 24 \\
\hline 12 & 24 & 24.7 \\
\hline 13 & 25 & 25.2 \\
\hline 14 & 26 & 27 \\
\hline 15 & 26.8 & 28 \\
\hline
\end{tabular}

- $\quad$ Two students of preceding and succeeding role number, who were non obese chosen as controls in the ratio of $1: 2$.

- Controls: For each case two controls were selected. Succeeding and preceding role numbers and sex matched students were chosen as controls.

- Physical activity: was assessed by questionnaire method.

To assess the obesity of parents, height and weight of the parents was measured and BMI was calculated. Parents whose $\mathrm{BMI}>30$ were considered as obese. Information regarding education, occupation and income (monthly) was collected by parents. To determine the association of life style influencing factors of obesity in children, mothers were interviewed in presence of children to gather information about their child's diet and daily (24 hour) activity. Number of hours spent in a day on these activities was considered for the study.

The data thus collected from mother was transferred to pretested proforma no. 2 especially designed for this study

\section{Physical Activity}

Outdoor playing (both at school and outside), Walking, Cycling, Swimming and Physical training in school and any other such energy spending activities were considered as physical activity.

\section{Statistical Analysis}

Data analysis was done using SPSS version 17. Prevalence of obesity was expressed in number and percentage. Chi- Square Test was used to find out the association between obesity. For all the tests $P$ value of 0.05 or less was considered for statistical significance

\section{RESULTS}

Out of 2000 children 66 were obese. The prevalence was $3.3 \%$ in school children in the age group of 6-15 years in three affluent schools of Tumkur.

In our study, Prevalence of obesity was more in boys $(3.47 \%)$ on comparison to girls (3.04\%).

There is increased prevalence of obesity in age group of six $(4.26 \%)$, eleven $(4.37 \%)$ and twelve $(5.64 \%)$ years.

The Prevalence of obesity was more in Hindus (3.34\%) when compared to Muslims and other religions $(2.43 \%)$

In this study $77.2 \%$ cases spent less than 2 hrs in a day and $22.7 \%$ cases spent more than 2 hrs in physical activities. Prevalence of obesity was more in children who spent less than 2 hrs in a day in physical activities. This was statistically significant.

In $72.41 \%$ of obese children and $65.68 \%$ of non obese children, family income was more than 15000Rs but this was not significant stastically.

Our study shows that children belonging to higher socio economic status were more obese than lower

Table 1: Prevalence of Obesity

\begin{tabular}{|c|c|c|c|}
\hline Number of Children Studied & Obese Children & Non-obese Children & Prevalence \\
\hline \hline 2000 & 66 & 1934 & $3.5 \%$ \\
\hline
\end{tabular}

Table 2: Prevalence of Obesity by Sex

\begin{tabular}{|c|c|c|c|c|c|}
\hline \multirow{2}{*}{ Sex } & \multirow{2}{*}{ Number of Children } & \multicolumn{2}{|c|}{ Obese Children } & \multicolumn{2}{c|}{ Non-obese Children } \\
\cline { 2 - 5 } & & Obese & $\%$ & Non obese & $\%$ \\
\hline \hline BOYS & 1180 & 41 & 3.47 & 1139 & 96.52 \\
\hline GIRLS & 820 & 25 & 3.04 & 795 & 96.95 \\
\hline TOTAL & 2000 & 66 & 3.30 & 1934 & 96.70 \\
\hline
\end{tabular}




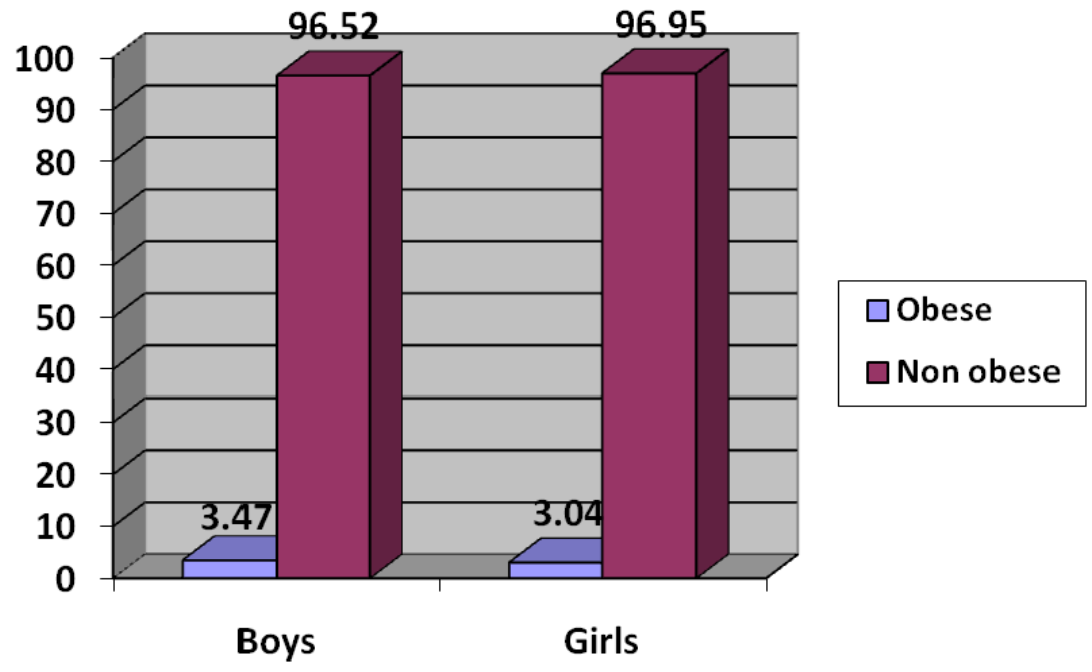

Figure 1: Prevalence of obesity by sex.

Table 3: Prevalence of Obesity by Age

\begin{tabular}{|c|c|c|c|}
\hline \multirow{2}{*}{ Age } & Number of Children & Number & Obese Children \\
\cline { 2 - 4 } & & 8 & 4.26 \\
\hline \hline 6 & 258 & 4 & 2.56 \\
\hline 7 & 156 & 9 & 3.10 \\
\hline 8 & 290 & 9 & 3.33 \\
\hline 9 & 270 & 6 & 3.10 \\
\hline 10 & 193 & 8 & 4.37 \\
\hline 11 & 183 & 10 & 5.64 \\
\hline 12 & 177 & 4 & 2.15 \\
\hline 13 & 186 & 5 & 2.87 \\
\hline 14 & 174 & 3 & 2.65 \\
\hline 15 & 113 & 66 & 3.3 \\
\hline
\end{tabular}

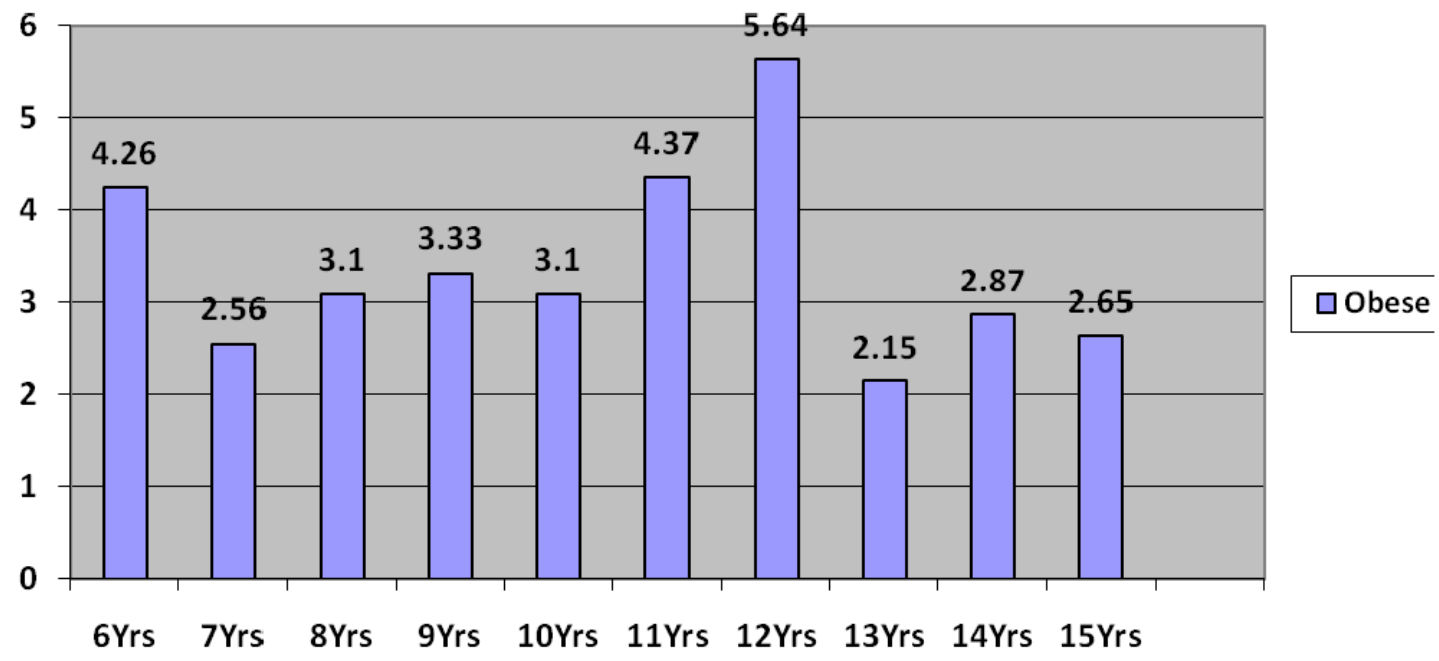

Figure 2: Prevalence of obesity by age. 
Table 4: Prevalence of Obesity by Religion

\begin{tabular}{|c|c|c|c|c|c|}
\hline \multirow{2}{*}{ Religion } & Number of Children & \multicolumn{2}{|c|}{ Cases } & \multicolumn{2}{c|}{ Controls } \\
\cline { 3 - 6 } & & Number & $\%$ & 3.34 & 1848 \\
\hline \hline Hindu & 1912 & 64 & 2.43 & 80 & 96.66 \\
\hline Muslim & 82 & 0 & 0 & 6 & 100 \\
\hline Other Religions & 6 & 0 & & 67.57 \\
\hline
\end{tabular}

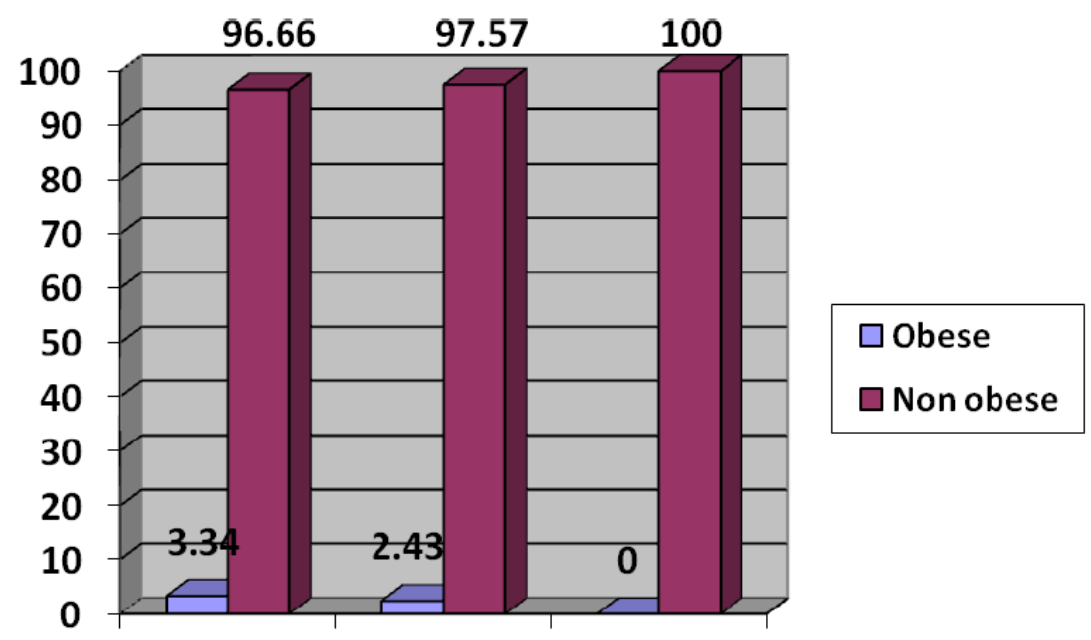

Hindu Muslim Others

Figure 3: Prevalence of obesity by age.

Table 5: Association between Physical Activity and Obesity

\begin{tabular}{|c|c|c|c|c|}
\hline Time Spent in Physical Activities & Cases & $\%$ & Controls \\
\hline \hline$<2 h r s$ & 51 & 77.27 & 25 & 18.93 \\
\hline$>$ hhrs & 15 & 22.72 & 107 & 132 \\
\hline TOTAL & 66 & 100 & 100 \\
\hline
\end{tabular}

$X^{2}=63.29 ; d f=1 ; p=0.001$.

Table 6: Association between Parents Income and Children's Obesity

\begin{tabular}{|c|c|c|c|}
\hline Family Income & Cases & Controls & Total \\
\hline \hline$<15000$ & 8 & 58 & 66 \\
\hline$>15000$ & 21 & 111 & 132 \\
\hline Total & 29 & 169 & 198 \\
\hline
\end{tabular}

$X^{2}=0.435 ; d f=1 ; P=0.05$.

Table 7: Association between Parents Education and Children's Obesity

\begin{tabular}{|c|c|c|c|}
\hline Education & Cases & Controls & Total \\
\hline \hline Upto $10^{\text {th }}$ Std & 43 & 78 & 121 \\
\hline College $\left(11^{\text {th }}\right.$ Std $)$ and above & 23 & 54 & 77 \\
\hline Total & 66 & 132 & 198 \\
\hline
\end{tabular}

$X^{2}=0.68 ; d f=1 ; P=0.05$. 
socio economic status but this was not significant stastically.

\section{DISCUSSION}

Our study shows prevalence of obesity in schoolchildren aged $6-15 y$ rs was $3.3 \%$ in three affluent schools of Tumkur. In a study conducted in New Delhi by Sheetal Monga on 1238 school children of 7 to 9 years of age prevalence of obesity was $6.22 \%$ [7]. In a study on 10-16 years old affluent school children in Delhi in 2002 prevalence of obesity was $7.4 \%$ [8]. These two studies have shown more prevalence compared to our studies. On the other hand study in Kerala by Raj M in the age group of 5-11 years in 2005, showed lesser prevalence of $1.89 \%$ [3].

Studies have shown that the prevalence has reached $6-18 \%$ in school children in different parts of the India [7-10].

Reported Global prevalence of childhood obesity varies from $30 \%$ to $2 \%$ in different parts of the world [11].

Prevalence of obesity in our study was more in boys $(3.47 \%)$ on comparison with girls (3.04\%). Study by Ramachandran [9] shows increased prevalence of obesity for Boys. There is increased prevalence of obesity in age group of six (4.26\%), eleven (4.37\%) and twelve (5.64\%) years. Pubertal spurt could be the cause for increased prevalence in 11-12 years. In this study $77.2 \%$ cases spent less than 2 hrs in a day and $22.7 \%$ cases spent more than 2 hrs in physical activities. It shows prevalence of obesity was more in children who spent less than $2 \mathrm{hrs}$ in a day in physical activities. This was statistically significant.

Our study results are similar to the studies of Sheethal Monga [7] and Laxmaiah A [12].

Physically active children are less prone for obesity. Increase in duration of physical activity showed decrease in development of obesity. On the other hand increase in duration of sedentary activity showed higher risk of developing obesity. Beaton GH (1976) has pointed out about many studies showing almost characteristic differences in the recreational and leisure activities of obese and non obese persons, the former choosing activities involving less energy expenditure [13].

Prevalence of obesity was more in Hindus (3.34\%) than Muslims and other religions (2.43\%). Cultural differences in food habits between different religions might have an influence on the prevalence of obesity.

Education status of both parents plays a role in determining obesity on children. WHO (1997) reports level of education appears to be inversely associated with body weight in developed countries. Our study shows that there is no association between parents education and income to the obesity in children. Unfortunately little is known about relationship between education level and obesity in developing countries.

\section{CONCLUSION}

Prevalence of obesity in schoolchildren aged 6$15 y$ rs is $3.3 \%$ in three affluent schools of Tumkur. Prevalence of obesity was more among boys on comparison with girls.

Physical activity was the significant influencing factor of obesity in school children.

\section{RECOMMENDATIONS}

Knowledge regarding healthy lifestyles healthy food habits should be inculcated to school children through curriculum and teachers should be trained. Necessary measures to be taken to educate public to build healthy future generation by creating awareness to combat child hood obesity. Periodic health checkups in school should be made compulsory. Large scale epidemiological studies should be conducted in different parts of world to understand the knowledge gap to design intervention strategies accordingly.

\section{LIST OF ABBREVIATIONS USED}

$$
\begin{aligned}
& \text { WHO }=\text { World Health Organization } \\
& \text { BMI }=\text { Body Mass Index } \\
& \text { NCHS }=\text { National Center for Health Statistics }
\end{aligned}
$$

\section{COMPETING INTERESTS}

The authors declare that they have no competing interests.

\section{ACKNOWLEDGEMENTS}

We thank the three affluent schools of Tumkur, students and staff of the schools for their cooperation during the study. We acknowledge the support provided by the management of Shridevi Institute of Medical Sciences and Research Hospital and office 


\section{staff of Department of Community Medicine for this} research work.

\section{REFERENCES}

[1] Shetty PS. Nutrition transition in India. Public Health Nutr 2002; 5: 175-82. http://dx.doi.org/10.1079/PHN2001291

[2] Sirard JR, Pate RR. Physical activity and assessment in children and adolescents. Sports Med 2001; 31: 439-54. http://dx.doi.org/10.2165/00007256-200131060-00004

[3] Raj M, Sundaram KR, Paul M, Deepa AS, Kumar RK. Obesity in Indian children: Time trends and relationship with hypertension. Natl Med J India 2007; 20: 288-93.

[4] Canning $\mathrm{H}$. Obesity its possible effect on college acceptance. New Engl J Med 1966; 275: 1172-4. http://dx.doi.org/10.1056/NEJM196611242752107

[5] WHO-TRS 894. Obesity preventing and managing global epidemic; Geneva; WHO 2000.

[6] Growth Charts. [serial online] Available from: URL: http://www.cdc.gov/growthcharts.htm Accessed November 15, 2009

[7] Sheethal M. Obesity among school children (7-9 years old) in India, prevalence and related factors; public health and the environment: the 132nd annual meeting of APHA, Nov 6-10 2004.

[8] Kapil U, Singh P, Pathak P, Dwivedi SN, Bhasin S Prevalence of obesity among affluent adolescent school children in Delhi. Indian Paediatr 2002; 39: 449-52.

[9] Ramachandran A, Snehalatha C, Vinitha R, et al. Prevalence of overweight in urban Indian adolescent school children. Diabetes Res Clinic Pract 2002; 57: 185-90. http://dx.doi.org/10.1016/S0168-8227(02)00056-6

[10] Gupta AK, Ahmed AJ. Childhood obesity and hypertension. Indian Paediatr 1990; 39: 333-7.

[11] Bhave S, Bavdekar A, Otiv M. IAP National Task Force for Childhood Prevention of Adult Diseases: Childhood Obesity. IAP National Task Force for Childhood Prevention of Adult Diseases: Childhood Obesity. Indian Paediatr 2004; 41: 55975.

[12] Laxmaiah A, Nagalla B, Vijayaraghavan K, Nair M. Factors affecting prevalence of overweight among 12- to 17-year-old urban adolescents in Hyderabad, India. Obesity 2007; 15 1384-90.

http://dx.doi.org/10.1038/oby.2007.165

[13] Beaton GH. Nutritional problems of affluence. Nutrition in preventive medicine. WHO: 1976; No.62: 482-9.

Received on 04-05-2015

Accepted on 21-05-2015

Published on 01-06-2015

http://dx.doi.org/10.6000/1929-4247.2015.04.02.8

(C) 2015 Kumar et al.; Licensee Lifescience Global.

This is an open access article licensed under the terms of the Creative Commons Attribution Non-Commercial License (http://creativecommons.org/licenses/by-nc/3.0/) which permits unrestricted, non-commercial use, distribution and reproduction in any medium, provided the work is properly cited. 